\title{
Senam Otak (Brain Gym) Berpengaruh terhadap Tingkat Stres pada Anak Usia Sekolah Kelas V di SD Negeri Pokoh 1 Wedomartani Ngemplak Sleman Yogyakarta
}

\author{
Yunita Dikir ${ }^{1}$, Atik Badi'ah², Lala Budi Fitriana ${ }^{3}$
}

1,2,3 Universitas Respati Yogyakarta

Jalan Raya Tajem Km 1,5, Maguwoharjo, Depok, Kecamatan Sleman, Daerah Istimewa Yogyakarta Email: Ibfitriana@gmail.com

\begin{abstract}
Kegiatan belajar yang berlebihan dapat menimbulkan stres pada anak. Penyebab anak stres di Indonesia mencapai 82,8\% yang berasal dari rutinitas anak yang sangat padat. Data Komisi Naional perlindungan anak mencatat rata-rata 200 kasus setiap bulan meningkat 28\%. Senam otak (brain gym) digunakan sebagai salah satu kegiatan untuk mengatasi masalah stres pada anak dan meningkatkan daya ingat. Tujuan penelitian untuk mengetahui pengaruh senam otak (brain gym) terhadap tingkat stres pada anak usia sekolah kelas $V$ di SD Negeri Pokoh 1 Wedomartani Ngemplak Sleman Yogyakarta. Jenis penelitian yang digunakan adalah quasi experiment dengan rancangan One-Group pre and post-test design. Subyek penelitian yaitu seluruh anak kelas V di SD Negeri Pokoh 1 Wedomartani Ngemplak Sleman Yogyakarta tahun 2014 sebanyak 36 siswa. Pengambilan sampel dengan teknik total sampling dan analisis data menggunakan uji wilcoxon. Hasil tingkat stres pada anak sebelum diberi perlakuan senam otak (brain gym) sebagian besar berada pada kategori sedang (50,0\%) dan sesudah diberi perlakuan senam otak (brain gym) sebagian besar tingkat stres pada anak berada pada kategori normal (75,0\%). Uji statistik menggunakan uji wilcoxon menunjukan hasil yaitu p-value 0,000<0,05. Kesimpulan ada pengaruh senam otak (brain gym) terhadap tingkat stres sebelum dan sesudah perlakuan pada anak kelas V di SD Negeri Pokoh 1 Wedomartani Ngemplak Sleman Yogyakarta.
\end{abstract}

Abstrak

Kata Kunci: senam otak (brain gym), tingkat stres, anak usia sekolah

\section{The Effect of Brain Gym on Stress Levels in School-Age Children of Fifth Grade at SD Negeri Pokoh 1 Wedomartani Ngemplak Sleman Yogyakarta}

\begin{abstract}
Learning activities may cause excessive stress IN children. $82.8 \%$ of the causes of stress in children in Indonesian are from their very tight routine. Data of the National Commission for Children Protection show an average of 200 cases per month which increases $28 \%$. Brain gym is used as one of the activities to address the issue of stress in children and to improve memory. This research is aimed at identifying the effect of brain gym on stress levels in school-age children of fifth grade at SD Negeri Pokoh 1 Wedomartani Ngemplak Sleman Yogyakarta. This research is a quasi-experimental research with one-group pre and post-test design. The subjects of the research were all fifth grade students at SD Negeri Pokoh 1 Wedomartani Ngemplak Sleman Yogyakarta in 2014, numbering 36 students. Sampling employed a total sampling and data were analyzed using the wilcoxon test. The results showed that the stress level of children before the brain gym given was mostly in the moderate category $(50.0 \%)$ and after the brain gym given was mostly in the normal category (75.0\%). The statistical test using the wilcoxon test generated $p$-value of $0.000<0.05$. Conclusion, there was a significant effect of brain gym on stress levels before and after treatment in the fifth grade students at SD Negeri Pokoh 1 Wedomartani Ngemplak Sleman Yogyakarta.
\end{abstract}

Keywords: brain gym, stress levels, school-age children

Info Artikel:

Artikel dikirim pada 23 Maret 2016

Artikel diterima pada 23 April 2016

DOI : http://dx.doi.org/10.21927/jnki.2016.4(2).70-74 


\section{PENDAHULUAN}

Anak-anak usia sekolah (school-age child) adalah anak-anak yang sedang belajar di sekolah. Anak-anak ini tergolong pada tahap perkembangan akhir masa kanak-kanak (middle childhood). Usia 6 sampai 10 tahun, perkembangan biofisik anak usia 6 sampai 10 tahun mengalami masa stabil tidak seperti pada anak usia 0 sampai 6 tahun. Usia 10 sampai 12 tahun, anak memasuki masa prapubertas, perubahanperubahan biofisik akan dirasakan kembali terutama pada organ-organ seksual (1).

Perkembangan yang dikemukakan oleh Erikson, anak-anak usia 10 sampai 12 tahun berada dalam tahapan industry versus inferriority (kerajinan dan inferioritas) dimana masa ini anak-anak memulai kesiapan menghadapi tugas-tugas yang diberikan, sibuk dengan situasi-situasi yang produktif, dapat melakukan sesuatu bersama-sama dengan orang lain. Masa ini pula konsep diri pada anak mulai terbentuk (2).

Catatan lembaga konseling person growth 4 dari 5 anak usia 2-15 tahun mengalami stres. Komisi Nasional Perlindungan anak juga mencatat di tahun 2011 terjadi peningkatan berbagai bentuk pengabaian dan hak anak Indonesia. Komnas perlindungan anak menerima laporan rata-rata 200 kasus setiap bulan dan meningkat $28 \%$ dari tahun sebelumnya. $82,8 \%$ penyebab anak stres di Indonesia berasal dari padatnya aktivitas anak atau rutinitas anak yang sangat padat sehingga anak merasa jenuh dan kurang memiliki kesempatan untuk bersantai dan bermain untuk menyalurkan energi emosional dan ketegangan yang dialaminya (3).

Riset terbaru American Alliance for Health, Physical Education and Dance National Convention, menyatakan bahwa anak yang tidak mampu belajar dapat dibantu dengan memberikan pelatihan berupa olahraga, konsumsi makanan sehat dan mengurangi stres (4). Salah satu intervensi yang dapat dilakukan pada anak dengan masalah stres antara lain melalui senam otak. Senam otak atau lebih dikenal sebagai brain gym sebenarnya adalah serangkaian gerakan sederhana yang dilakukan untuk merangsang kerja dan fungsi otak secara maksimal. Awalnya senam otak dimanfaatkan untuk anak yang mengalami gangguan hiperaktif, kerusakan otak, sulit konsentrasi dan depresi. Namun dalam perkembangannya semua orang bisa memanfaatkan untuk beragam kegunaan. Saat ini, di negara bagian Amerika dan Eropa senam otak sudah banyak digemari karena banyak orang yang merasa terbantu melepaskan stres, menjernihkan pikiran, meningkatkan daya ingat dan sebagainya (5).

Secara umum penelitian ini bertujuan untuk mengetahui pengaruh senam otak terhadap tingkat stres pada anak usia sekolah kelas V SD Negeri Pokoh 1 Wedomartani Ngemplak Sleman Yogyakarta. Secara khusus bertujuan untuk mengetahui tingkat stres pada anak usia sekolah, diketahui tingkat stres pada anak usia sekolah di SD Negeri Pokoh 1 Wedomartani Ngemplak Sleman Yogyakarta sesudah dilakukan senam otak (brain gym).

\section{BAHAN DAN METODE}

Jenis penelitian ini adalah quasi experiment dengan rancangan one-group pre and post-test design. Tempat penelitian yaitu di SD Negeri Pokoh 1 Wedomartani Ngemplak Sleman Yogyakarta. Penelitian ini dilaksanakan pada tanggal 18 April sampai 30 Mei 2014. Besar sampel dalam penelitian ini diambil dengan teknik total sampling, yaitu seluruh anak kelas V SD Negeri Pokoh 1 Wedomartani Ngemplak Sleman Yogyakarta dengan responden sebanyak 36 anak. Instrumen penelitian menggunakan kuesioner DASS (Depression Anxiety Stress Scale) 42, alat ukur dalam penelitian tersebut berupa kuesioner yang terdiri dari 14 pertanyaan. Pada penelitian tidak menggunakan uji validitas dan reliabilitas karena dalam penelitian ini menggunakan kuesioner yang di adopsi dari Lovibond dan Lovibond (6).

\section{HASIL DAN BAHASAN}

\section{Karakteristik Subjek Penelitian}

Responden penelitian adalah semua anak kelas V SD Negeri Pokoh 1 Wedomartani Ngemplak Sleman Yogyakarta sebanyak 36 anak terdiri dari 21 anak laki-laki dan 15 anak perempuan. Sebanyak 36 anak yang mengalami drop out berjumlah 4 anak karena pulang lebih awal dan tidak mengikuti senam otak (brain gym) sampai evaluasi akhir. Jadi total responden dalam penelitian adalah sebanyak 32 anak. Karakteristik responden dalam penelitian meliputi jenis kelamin, umur, pre test dan post test sebelum dan sesudah melakukan tindakan senam otak (brain gym). 
Tabel 1. Karakteristik Responden Berdasarkan Jenis Kelamin dan Umur pada Anak kelas V di SD Negeri Pokoh 1 Wedomartani Ngemplak Sleman Yogyakarta

\begin{tabular}{lcc}
\hline \multicolumn{1}{c}{ Karakteristik } & $\mathbf{f}$ & $\%$ \\
\hline $\begin{array}{l}\text { Jenis Kelamin } \\
\text { Laki-Laki }\end{array}$ & 19 & 59,4 \\
Perempuan & 13 & 40,6 \\
Umur (Tahun) & & \\
10 & 7 & 21,9 \\
11 & 15 & 46,9 \\
12 & 8 & 25,0 \\
13 & 2 & 6,3 \\
Total & 32 & 100 \\
\hline
\end{tabular}

Sumber: Data Primer Tahun 2014

Berdasarkan Tabel 1 menunjukan bahwa karakteristik responden sebagian besar mempunyai jenis kelamin laki-laki sebanyak 19 anak $(59,4 \%)$ dan responden berusia 11 tahun yang berjumlah 15 anak $(46,9 \%)$.

\section{Tingkat Stres pada Anak Sebelum Dilakukan Senam Otak (Brain Gym)}

Berdasarkan Tabel 2 menunjukan bahwa sebagian besar tingkat stres pada anak sebelum dilakukan perlakuan berada dalam kategori ringan sebanyak 13 anak $(40,6 \%)$ dan kategori sedang sebanyak 16 anak $(50,0 \%)$.

Tabel 2. Distribusi Frekuensi Tingkat Stres pada Anak Sebelum Dilakukan Senam Otak (Brain Gym) di SD Negeri Pokoh 1 Wedomartani Ngemplak Sleman Yogyakarta Mei 2014

\begin{tabular}{lcc}
\hline \multirow{2}{*}{ Tingkat Stres } & \multicolumn{2}{c}{ Kelompok Kasus } \\
\cline { 2 - 3 } & $\mathbf{n}$ & $\%$ \\
\hline Normal & 3 & 9,5 \\
Ringan & 13 & 40,6 \\
Sedang & 16 & 50,0 \\
Total & 32 & 100 \\
\hline
\end{tabular}

Sumber: Data Primer Tahun 2014

Berdasarkan hasil penelitian pada Tabel 1 tingkat stres anak sebelum dilakukan senam otak (brain gym) menunjukan hasil pada kategori sedang sebanyak 16 anak (50,0\%). Penelitian yang dilakukan sesuai dengan penelitian yang telah dilakukan oleh Sari yang menyatakan bahwa stres anak terbesar berada pada kategori stres sedang. Masalah ini bersumber dari keluarga misalnya kurang perhatian dan tuntutan dari orang serta bersumber dari sekolah yang berkaitan dengan tugas sekolah misalnya pemberian tugas mata pelajaran yang berlebihan yang diberikan setiap hari (7).

Penelitian yang dilakukan oleh Noviekayanti yang menyatakan bahwa penyebab stres dikarenakan tuntutan dari orang tua. Pemberian tugas yang berlebihan dari orang tua menyebabkan anak kurang dapat bermain dengan kelompoknya sehingga menimbulkan ketegangan dan perasaan tidak nyaman (8). Berdasarkan hasil wawancara yang dilakukan, terdapat 11 anak mengatakan bahwa ada pemberian tugas tambahan yang diberikan dari orang tua yaitu dengan mengikuti les tambahan diluar pelajaran jam sekolah anak. Hal inilah yang memicu terjadinya stres pada anak.

Hal senada juga dijelaskan oleh Wibisono, bahwa anak-anak bisa mengalami stres karena kegiatan sehari-harinya. Banyaknya tuntutan dari sekolah dan juga tuntutan dari orang tua dalam meningkatkan prestasi belajar anak sehingga menambah beban anak menjadi berat. Rasa tertekan inilah yang dapat menimbulkan dampak negatif pada anak, baik secara fisik maupun psikis (9).

\section{Tingkat Stres pada Anak Sesudah Dilakukan Senam Otak (Brain Gym)}

Berdasarkan Tabel 3 menunjukan bahwa sebagian besar tingkat stres pada anak sesudah dilakukan perlakuan senam otak (brain gym) berada dalam kategori normal sebanyak 24 anak $(75,0 \%)$.

Tabel 3. Distribusi Frekuensi Tingkat Stres pada Anak Sesudah Dilakukan Senam Otak (Brain Gym) di SD Negeri Pokoh 1 Wedomartani Ngemplak Sleman Yogyakarta Mei 2014

\begin{tabular}{lcc}
\hline \multirow{2}{*}{ Tingkat Stres } & \multicolumn{2}{c}{ Kelompok Kasus } \\
\cline { 2 - 3 } & $\mathbf{n}$ & $\%$ \\
\hline Normal & 24 & 75,0 \\
Ringan & 6 & 18,8 \\
Sedang & 2 & 6,3 \\
Total & 32 & 100 \\
\hline
\end{tabular}

Sumber: Data Primer Tahun 2014

Berdasarkan hasil penelitian Tabel 3 tingkat stres pada anak usia sekolah sesudah diberi senam otak (brain gym) selama 7 minggu didapatkan tingkat stres sebagian besar dalam kategori normal sebanyak 24 anak $(75,0 \%)$ saat dalam pemberian perlakuan senam otak (brain gym) anak melakukan 
gerakan dengan penuh konsentrasi dan rasa nyaman. Sedangkan sebanyak 2 anak $(6,3 \%)$ masih tetap berada dalam kategori sedang disebabkan anak kurang berkonsentrasi saat pemberian perlakuan senam otak (brain gym) berlangsung.

Hasil penelitian didukung oleh penelitian yang dilakukan Widyastuti dan Purwanyo tentang efektivitas brain gym dalam menurunkan stres pada anak. Hasil penelitian menunjukan bahwa terjadinya penurunan yang signifikan dalam meningkatkan stres pada anak setelah diberikan gerakan senam otak (brain gym) (10).

Sularyo dan Setyo memaparkan bahwa gerakan senam otak (brain gym) dapat meningkatkan dan mengembangkan kedua belah hemisfer yaitu hemisfer kiri dan kanan (11). Keadaan stres, batang otak merupakan fokus aktivitas otak yang berfungsi untuk survival (tendon guard reflex) bila menghadapi bahaya. Refleks bisa terkunci atau terhambat oleh lingkungan, stres emosi seperti pekerjaan, ujian serta menghambat akses ke memori (sistem limbik) dan kemampuan berpikir (neo-cortex). Senam otak dapat memperbaiki kemampuan semua area otak dengan cara mengaktivasi semua fungsi sehingga sangat bermanfaat bagi anak seperti kemampuan untuk berpikir jernih, memecahkan masalah, kemampuan komprehensi, organisasi dan komunikasi secara efektif. Sesuai dengan pendapat Ayinosa yang menyatakan bahwa brain gym dapat memberikan manfaat yaitu dengan menciptakan suasana belajar lebih rileks dan senang sehingga tidak menimbulkan perasaan tertekan pada anak yang dapat memberikan dampak negatif (12).

\section{Analisis Bivariat Pengaruh Senam Otak (Brain Gym) Terhadap Tingkat Stres pada Anak}

Berdasarkan Tabel 4 diketahui bahwa tingkat stres pada anak sebelum dilakukan senam otak (brain gym) pada kategori sedang sebanyak 16 anak $(50,0 \%)$ dan sesudah dilakukan senam otak (brain gym) sebagian besar tingkat stres pada anak berada pada kategori normal sebanyak 24 anak $(75,0 \%)$.

Berdasarkan hasil uji wilcoxon didapatkan nilai $p$-value $(p=0,000)<0,05$ maka disimpulkan bahwa ada pengaruh senam otak (brain gym) terhadap tingkat stres sebelum dan sesudah dilakukan perlakuan.

Hasil penelitian sesuai dengan penelitian yang telah dilakukan oleh Nuryanti dan Setiyo tentang efektifitas brain gym dalam menurunkan kecemasan dengan responden sebanyak 24 orang yang terbagi dalam 2 kelompok dengan masingmasing responden 12 orang sebagai kelompok eksperimen dan 12 orang lainya sebagai kelompok kontrol. Rata-rata nilai kecemasan sebelum dan sesudah diberikan senam otak (brain gym) pada kelompok eksperimen terjadi penurunan dan kelompok kontrol terjadi peningkatan. Hasil penelitian menunjukan bahwa latihan senam otak (brain gym) menurunkan kecemasan pada siswa saat menghadapi ujian sekolah (13).

Hasil penelitian didukung oleh penelitian yang telah dilakukan Sari, tentang pengaruh senam otak terhadap tingkat stres pada anak. Sampel berjumlah 60 responden yang terbagi dalam 2 kelompok (7). Rata-rata nilai tingkat stres sesudah diberikan senam otak (brain gym) pada kelompok eksperimen dan kontrol dapat dilihat pada Tabel 5.

Tabel 5. Tingkat Stres pada Anak Sesudah Dilakukan Senam Otak (Brain Gym) pada Kelompok Eksperimen dan Kelompok kontrol

\begin{tabular}{lcccc}
\hline Tingkat & \multicolumn{2}{c}{ Eksperimen } & \multicolumn{2}{c}{ Kontrol } \\
\cline { 2 - 5 } Stres & $\mathbf{n}$ & $\%$ & $\mathbf{n}$ & $\%$ \\
\hline Ringan & 13 & 43 & 7 & 23 \\
Sedang & 17 & 57 & 19 & 64 \\
Tinggi & 0 & 0 & 4 & 13 \\
\hline
\end{tabular}

Sumber: Data Primer Tahun 2014

Berdasarkan Tabel 5 diketahui nilai tingkat stres anak sesudah dilakukan senam otak (brain gym) pada kelompok eksperimen sebagian besar berada pada kategori sedang sebanyak 17 anak (57\%) sedangkan pada kelompok kontrol sebagian besar tetap berada pada kategori sedang sebanyak 19 orang (64\%). Dari hasil penelitian tersebut disimpulkan bahwa latihan senam otak dapat menurunkan tingkat stres pada anak usia sekolah.

Penelitian didukung oleh teori Dennison, brain gym dengan gerakan alami yang sehat seperti gerakan yang berada di dalam dimensi pemusatan antara lain minum air putih, saklar otak, tombol bumi, tombol imbang, tombol angkasa, menguap berenergi, pasang telinga, kait relaks, dan titik positif bisa dilakukan untuk menyegarkan fisik dan pikiran siswa setelah menjalani proses pembelajaran yang membutuhkan konsentrasi tinggi yang mengakibatkan kelelahan pada otak (14).

Kelelahan pada otak dapat menyebabkan stres. Stres dalam aktivitas tubuh dikendalikan 
oleh system saraf simpatis. Pada saat tingkat stres meningkat, tingkat adrenalin naik sehingga terjadi penurunan tegangan di membran sel-sel saraf dan menyiapkan tubuh untuk bereaksi. Tubuh bereaksi dan memusatkan energi elektrik menjauhi neocortex dan ke sistem saraf simpatik. Gerakan meningkatkan energi dan menunjang sikap positif mengaktifkan neocortex sehingga dapat mengfokuskan kembali energi elektrik kepusatpusat yang berpikir positif (15). Sehingga stres yang menurun menyebabkan penurunan stimulasi medulla dan kelenjar adrenal untuk mengeluarkan hormon epinefrin dan nonepinefrin (katekolamin).

Senam otak (brain gym) yang dilakukan secara benar dan teratur pada anak membuat bagianbagian otak dapat bekerjasama sehingga stres akan berkurang dan otak semakin baik serta dapat meningkatkan daya ingat anak, mengoptimalkan motorik halus, meningkatkan konsentrasi dan menjaga badan agar tetap relaks (16). Berdasarkan hasil penelitian dan teori yang mendukung bahwa ada pengaruh senam otak (brain gym) dalam menurunkan tingkat stres pada anak.

\section{SIMPULAN DAN SARAN}

Tingkat stres pada anak sebelum dilakukan senam otak (brain gym) di SD Negeri Pokoh 1 Wedomartani Ngemplak Sleman Yogyakarta sebagian besar berada pada kategori sedang. Tingkat stres pada anak sesudah dilakukan senam otak (brain gym) di SD Negeri Pokoh 1 wedomartani Ngemplak Sleman Yogyakarta sebagian besar terjadi penurunan pada kategori normal. Terdapat perbedaan tingkat stres sebelum dan sesudah perakuan senam otak (brain gym) pada anak di SD Negeri Pokoh 1 Wedomartani Ngemplak Sleman Yogyakarta.

Bagi IImu Keperawatan Anak diharapkan dapat menggunakan senam otak (brain gym) sebagai salah satu kegiatan dalam memberikan asuhan keperawatan untuk mengatasi stres pada anak. Bagi guru olahraga SD Negeri Pokoh 1 Wedomartani Ngemplak Sleman Yogyakarta diharapkan dapat mengenalkan kegiatan senam otak (brain gym) kepada siswa dan memasukan kegiatan senam otak (brain gym) dalam agenda sekolah.

\section{RUJUKAN}

1. Harris M, Butterworth G. Developmental Psychology. A student's Handbook. New York: Psychology Press; 2004.

2. Papalia DE, Olds SW, Feldman RD. A child's world: Infancy through adolescence. 9th ed. Boston: McGraw-Hill; 2002.

3. Fazriyati W. Mengapa anak usia 2-15 mengalami stres? [Internet]. 2012 [cited 2012 Mar 20]. Available from: http://female.kompas.com/ read/2012/03/1927597/

4. Dennison PE, Gail ED. Buku panduan lengkap brain gym-senam Otak. Jakarta: Grasindo; 2006.

5. Gunadi T. 24 Gerakan meningkatkan kecerdasan anak. Jakarta: Penebar Plus; 2009.

6. Lovibond SH, Lovibond PF. Manual for the Depression Anxiety Stres Scales. The Psychology Foundation of Australia Inc; 1995.

7. Sari OF. Pengaruh senam otak terhadap tingkat stres pada anak usia sekolah kelas 4 dan 5 di SD Negeri Wojo Bangunharjo Sewon Bantul Yogyakarta. Yogyakarta; 2010.

8. Noviekayati IGAA, Suroso. Pemetaan Penyebab stres pada anak di surabaya. J Univ 17 Agustus 1945. 2010;

9. Wibisono $\mathrm{S}$. Jangan biarkan anak stres [Internet]. 2009 [cited 2010 Jan 22]. Available from: http:// gentong-duit.blogspot.com/2009/11/janganbiarkan-anak-stres.html

10. Widyastuti R, Purwanyo S. Efektifitas brain gym dalam menurunkan stres pada anak. J Kesehat. 2009;2(2).

11. Sularyo TS, Setyo H. Senam otak. J Sari Pediatr. 2002;4(1):36-44.

12. Ayinosa 11. Brain Gym (Senam Otak) [Internet]. 2009 [cited 2010 Jan 15]. Available from: http:// book.store.co.id/2009

13. Nuryanti, Setiyo P. Efektifitas brain gym dalam menurunkan kecemasan siswa menghadapi ujian sekolah. J Kesehat. 2010;3(2).

14. Dennison PE. Brain gym and me. Jakarta: Gramedia; 2008.

15. Dennison PE, Gail E. Buku panduan lengkap brain gym. Jakarta: Gramedia; 2002.

16. Yanuarita FA. Memaksimalkan otak melalui senam otak (brain gym). Yogyakarta: Teranova Books; 2012. 